\title{
Benign Oral Cavity Neoplasm
}

National Cancer Institute

\section{Source}

National Cancer Institute. Benign Oral Cavity Neoplasm. NCI Thesaurus. Code C7607.

A non-metastasizing neoplasm arising from the oral cavity. Representative examples include hemangioma, tongue lipoma, and buccal mucosa papilloma. 